\title{
Strengthening of plain concrete beams using Strain Hardening Geopolymer Composites (SHGC) layers
}

\author{
Mohammed Haloob Al-Majidi
}

School of Environment and Technology, University of Brighton, Moulsecoomb, Brighton BN2 4GJ, UK

Department of Civil Engineering, College of Engineering, University of Basrah, Basrah, Iraq

Andreas Lampropoulos

School of Environment and Technology, University of Brighton, Moulsecoomb, Brighton BN2 4GJ, UK

Andrew B. Cundy

School of Ocean and Earth Science, University of Southampton, Southampton SO14 3ZH, UK.

Contact: $\underline{\text { m.almajidi@brighton.ac.uk }}$

\begin{abstract}
In this paper the application of novel, environmentally friendly, Strain Hardening Geopolymer Composites (SHGC) for the structural upgrade of existing concrete elements has been examined. The binder of these cement-free materials (SHGC) is different from that used in conventional cement based systems. Ternary geopolymer binder is used instead of Portland cement, which is activated by a low concentration and content of alkaline liquids (Potassium Silicate). The addition of two types of fibres (steel and PVA) has been examined in order to provide enhanced ductility and energy absorption characteristics. These novel materials have been used for the strengthening of concrete prisms. SHGC layers have been applied to conventional concrete elements and composite prisms with $100 \mathrm{~mm}$ breadth and depth and $500 \mathrm{~mm}$ span length and have been tested through flexural tests. The experimental results indicate that the addition of SHGC layers to existing concrete elements can considerably improve the flexural response of normal concrete. The proposed technique can lead to significantly higher flexural loading carrying capacity, while at the same time the ductility can be considerably improved, especially by the addition of PVA fibres which can also provide strain hardening properties.
\end{abstract}

Keywords: Geopolymer, SHGC, PVA fibres, steel fibres, fly ash and slag.

\section{Introduction}

Improvement of the structural performance of many existing infrastructure elements is an urgent need worldwide, especially in earthquake prone areas. Several techniques have been proposed for the strengthening of existing structures using conventional materials (e.g. Reinforced Concrete), Fibre Reinforced Polymers (FRPs) and, recently, Ultra High Performance Fibre Reinforced Concrete
(UHPFRC). These techniques have been proven to be relatively efficient but, as the need for sustainable development is becoming increasingly important, the application of new environmentally friendly materials for strengthening applications is becoming an area of growing interest.

Cement-based materials are characterised by an overall brittle behaviour with relatively low tensile strength and ductility [1]. One of the most widely used techniques for the enhancement of ductility, 
apart from the use of steel bars, is the addition of fibre reinforcement [2]. Fibre-reinforced cementitious composites can be used to considerably improve the service life of civil infrastructures by improving mechanical properties and durability [2, 3]. The mechanical behaviour of strengthened elements with SHCCs under chloride exposure and accelerated corrosion has been examined in previous studies $[4,5]$ and superior performance has been reported. This is attributed to the fibre-bridging action and self-healing properties of SHCCs [6]. Several studies have also focused on the application of SHCCs for seismic and non-seismic structural applications [7-9]. Based on these studies [8-9], enhanced structural performance of SHCCs elements under cyclic loading has been highlighted and this is attributed to the development of a multiple cracks phase rather than the localisation of the damage and the development of single crack followed by structural failure of the elements [10].

In the last few years, the application of SHCC material for new structures has become quite popular especially in applications with increased load and ductility demands [11, 12]. However, a high cement content is normally required for the SHCC mixture design and subsequently these materials are more energy intensive than conventional concrete.

In this study, the application of Strain Hardening Geopolymer Concrete (SHGC) has been examined for the strengthening of existing concrete elements. Geopolymer concrete is one of the most promising sustainable alternative to Ordinary Portland Cement (OPC). Geopolymers are inorganic by-product materials, rich in silicon (Si) and aluminium (Al) that react with alkaline activators to form three dimensional polymeric chains of sialate and poly(sialate) (Si-O-Al-O) [13, 14]. Utilization of geopolymer materials can reduce $80 \%$ of greenhouse gas emissions associated with material production, and overcome issues related to cement production and unregulated disposal of industrial materials [14-16].

The aim of the current study is to investigate the mechanical properties of SHGC materials and the flexural behaviour of SHGC layered concrete beams. An experimental investigation was conducted to evaluate the effectiveness of the application of SHGC layers for the structural strengthening of existing concrete elements. The effect of the incorporation of discontinuous steel (ST), and polyvinyl alcohol (PVA), fibres on flexural performance has been examined. The geopolymer matrix was produced using a ternary geopolymer binder (fly ash, slag and silica fume) mixed with a low content and concentration of potassium silicate alkaline activator.

\section{Preparation of SHGC material and testing}

The geopolymer mortar matrix adopted in the present work was based on geopolymer binder (fly ash, slag and silica fume) mixed with potassium silicate (with molar ratio equal to 1.25 ) and fine aggregate [17]. Silica sand of particle size less than $0.5 \mathrm{~mm}$ was used as the fine aggregate. The chemical compositions of the fly ash, slag and silica sand used are presented in Table 1.

Table 1. Chemical compositions of FA, GGBS and Silica Sand

\begin{tabular}{cccc}
\hline $\begin{array}{c}\text { Chemical compositions } \\
\text { (\%) }\end{array}$ & Fly ash & Slag & Silica Sand \\
\hline Silicon Dioxide, $\mathrm{SiO}_{2}$ & 59 & 35 & 99.73 \\
\hline Aluminium Oxide, $\mathrm{Al}_{2} \mathrm{O}_{3}$ & 23 & 12 & 0.1 \\
\hline Calcium Oxide, $\mathrm{CaO}$ & 2.38 & 40 & -- \\
\hline Ferric Oxide, $\mathrm{Fe}_{2} \mathrm{O}_{3}$ & 8.8 & 0.2 & 0.051 \\
\hline Sulphur Trioxide, $\mathrm{SO}_{3}$ & 0.27 & -- & -- \\
\hline Sodium Oxide, $\mathrm{Na}_{2} \mathrm{O}$ & 0.74 & -- & $<0.05$ \\
\hline Potassium Oxide, $\mathrm{K}_{2} \mathrm{O}$ & 2.81 & -- & 0.01 \\
\hline Magnesium Oxide, $\mathrm{MgO}$ & 1.39 & 10 & -- \\
\hline Loss on ignition, $\mathrm{LOI}$ & 6.7 & -- & 0.09 \\
\hline
\end{tabular}

Four different mixtures were examined in this study (Table 2). Total binder and silica sand quantities of $775 \mathrm{~kg} / \mathrm{m} 3$ and $1054 \mathrm{~kg} / \mathrm{m} 3$ respectively were used for all the examined mixes. Steel fibres with $13 \mathrm{~mm}$ length and $0.16 \mathrm{~mm}$ diameter, and PVA fibres with $12 \mathrm{~mm}$ length and $0.04 \mathrm{~mm}$ diameter, were used in the examined mixes (Figure 1). 


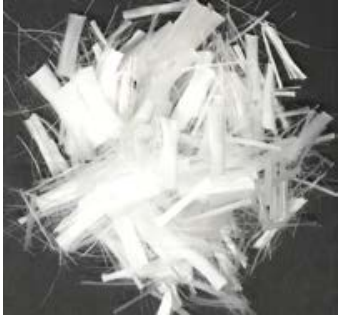

(a)

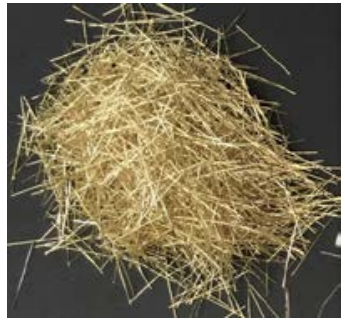

(b)
Figure 1. Fibres used in this study (a) steel fibres and (b) PVA fibres

Table 2. Mixture compositions at 28 days since it has been found that the examined mixes reach almost $80-90 \%$ of their maximum strength at this age. Compressive tests were conducted in a Denison Avery 2000KN testing machine with loading rate $45 \mathrm{KN}$ per minute [18] and four cubes per mix were tested. Flexural strength was determined through standard flexural tests of prism specimens $(100 * 100 * 500 \mathrm{~mm})$ at 28 days using an Instron universal testing machine. Span length was taken equal to $450 \mathrm{~mm}$ and the distance between the loading points was set at one third of the span length (Figure 2).

\begin{tabular}{cccccccccc}
\hline Mix ID & $\begin{array}{c}\text { FA/ } \\
\text { Binder }\end{array}$ & $\begin{array}{c}\text { Slag / } \\
\text { Binder }\end{array}$ & $\begin{array}{c}\text { SF/ } \\
\text { Binder }\end{array}$ & $\begin{array}{c}\text { OPC/ } \\
\text { binder }\end{array}$ & $\begin{array}{c}\mathrm{K}_{2} \mathrm{SiO}_{3} / \\
\text { Binder }\end{array}$ & $\begin{array}{c}\text { Water/ } \\
\text { Binder }\end{array}$ & $\begin{array}{c}\text { Fibre } \\
\text { Content }\end{array}$ & $\begin{array}{c}\text { Sand } \\
(\mathrm{Kg} / \mathbf{m 3})\end{array}$ & $\begin{array}{c}\text { Gravel } \\
(\mathrm{Kg} / \mathbf{m} 3)\end{array}$ \\
\hline PG & $50 \%$ & $40 \%$ & $10 \%$ & - & $12 \%$ & $25 \%$ & $0 \%$ & $136 \%$ & - \\
\hline PVAFRGC & $50 \%$ & $40 \%$ & $10 \%$ & & $12 \%$ & $25 \%$ & $2 \%$ PVA & $136 \%$ & - \\
\hline SFRGC & $50 \%$ & $40 \%$ & $10 \%$ & - & $12 \%$ & $25 \%$ & $3 \%$ ST & $136 \%$ & - \\
\hline NSC & - & - & - & $100 \%$ & - & $50 \%$ & $0 \%$ & $240 \%$ & $210 \%$ \\
\hline
\end{tabular}

For the Normal Strength Concrete (NSC) of the control specimens, Portland cement $(380 \mathrm{~kg} / \mathrm{m3})$, gravel $(920 \mathrm{~kg} / \mathrm{m3})$, sand $(800 \mathrm{~kg} / \mathrm{m3})$ and water $(190 \mathrm{~kg} / \mathrm{m} 3)$ were used. A Zyklos $75 \mathrm{~L}$ mixer (Pan Mixer ZZ $75 \mathrm{HE}$ ) was used for the mixing of the materials. Geopolymer binder (Silica fume, fly ash and slag) was placed first in the mixing drum, followed by alkaline liquid, and sand. The materials were dry mixed for $5 \mathrm{~min}$ and then the liquid phase was added and the mixer run for another $5 \mathrm{~min}$. After that steel fibre were gradually added to ensure uniform fibre dispersion in the geopolymer mix. Finally, silica sand was added to the mixer and the mixer was run for another $3 \mathrm{~min}$ to give a total mixing time of $13 \mathrm{~min}$ [17].

\section{Experimental results of SHGC material}

\subsection{Mechanical properties of SHGC material}

Compressive and flexural strength tests were conducted to evaluate the mechanical properties of SFRGC. Compressive strength was evaluated through standard compressive tests on $50 \mathrm{~mm}$ side cubes. The examined specimens were tested

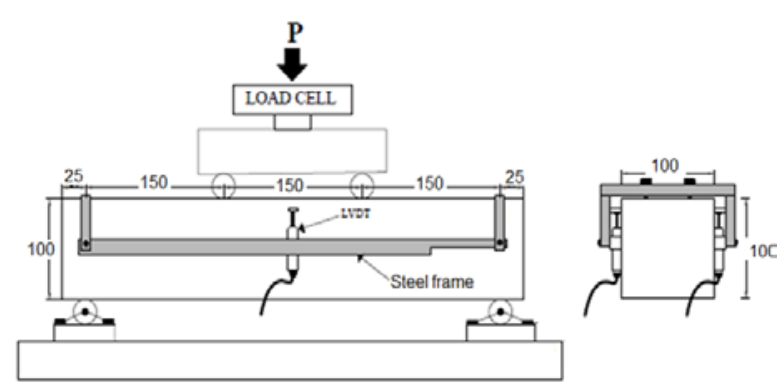

Figure 2. Bending specimen geometry and test set-up (dimensions in $\mathrm{mm}$ )

The testing machine was operated in a 'closed loop' at a fixed deflection rate of $0.24 \mathrm{~mm} / \mathrm{min}$. Two Linear Variable displacement Transducers (LVDTs) were attached to a 'yoke' (steel frame) which was used in order to eliminate any induced displacements at the supports during loading (Figure. 2). Load versus deflection results were obtained for the calculation of ultimate flexural strength, toughness and residual strength, based on ASTM C1609 [19]. The development of compressive strength and flexural strength for geopolymer mixes with and without fibres, are presented in Figure 3 and 4 respectively 


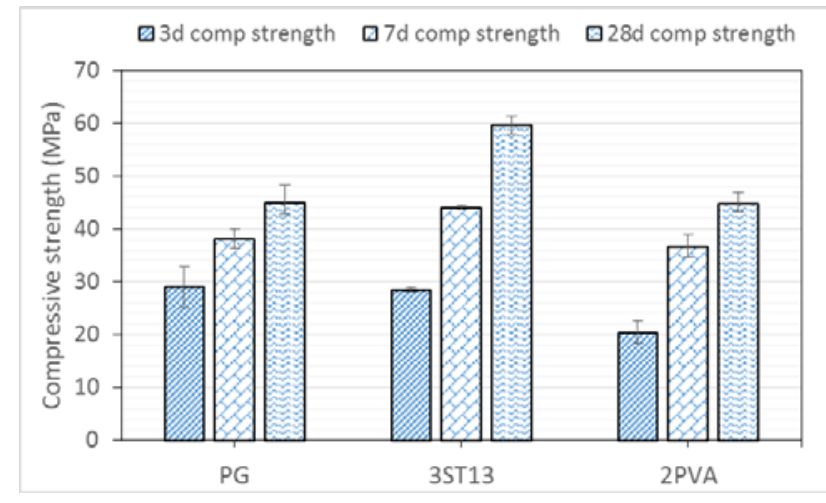

Figure 3. Compressive strength of plain geopolymer and FRGC mixtures

The results of Figure 3 indicate that the addition of fibres in the geopolymer material considerably impacted the compressive strength. The compressive strength of all the examined FRGCs was increased for longer curing periods. The 7 days compressive strength was enhanced by $31 \%$, $52 \%$ and $80 \%$ for PG, SFRGC and PVAFRGC mixtures respectively, compared with the respective values at 3 days. This observation is in agreement with the behaviour of OPC concrete, which undergoes a progressive hydration process and strength is gradually developed over time. The maximum compressive strengths were achieved at 28 days. The mean compressive strength at his age was found equal to $44 \mathrm{MPa}, 60$ $\mathrm{MPa}$, and $43 \mathrm{MPa}$ for PG, SFRGC and PVAFRGC mixtures, respectively.

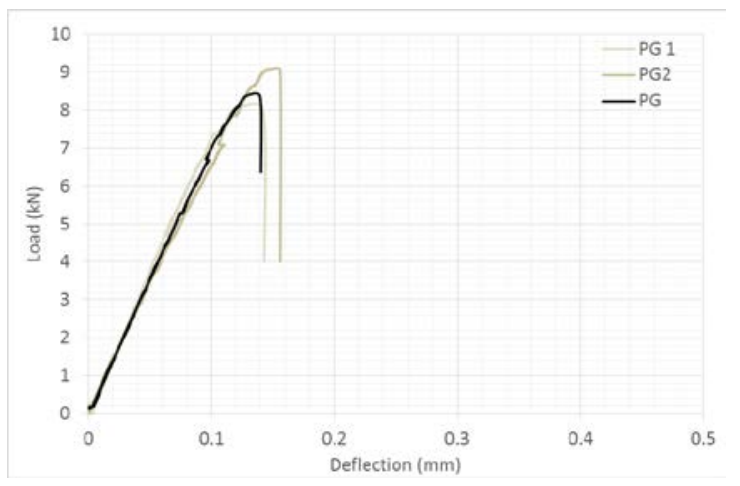

(a)

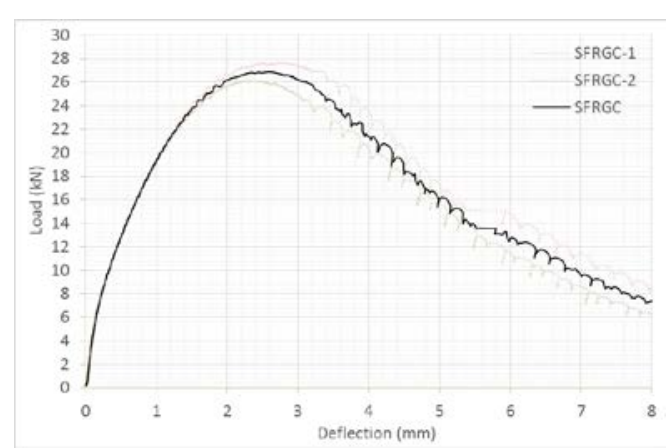

(b)

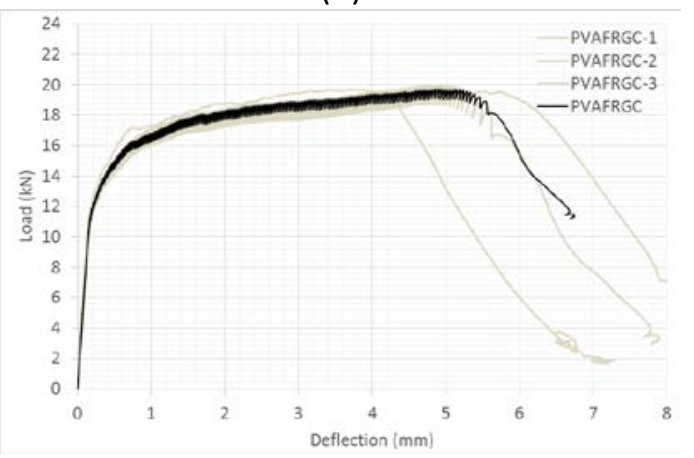

(c)

Figure 4. Flexural strength of (a) plain geopolymer, (b) SFRGC and (c) PVAFRGC mixture

Flexural load versus deflection behaviour of PG, SFRGC and PVAFRGC mixtures is illustrated in Figure 4. The load carrying capacity and the respective deflection values were considerably enhanced by the addition of fibres. The ultimate load capacity of plain geopolymer (PG) was increased by $140 \%$ and $240 \%$ for the mixture reinforced with steel fibre and PVA fibre, respectively. Also, the deflection at the peak load for SFRGC and PVAFRGC mixtures was almost 18 and 37 times higher compared to the respective value for the plain geopolymer (PG) mortar. The deflections at first cracking load and ultimate load were $0.6 \mathrm{~mm}$ and $2.5 \mathrm{~mm}$ for SFRGC. The PVAFRGC mixture showed significant deflection hardening behaviour and the respective characteristic points for first cracking and ultimate load were at $0.18 \mathrm{~mm}$ and $5.5 \mathrm{~mm}$, respectively (Figure 4c). The load deflection diagram showed that after the initial cracking, load was further increased up to quite high deflection vales, due to the fibre bridging action at the interface of the cracks. The ultimate flexural load value for SFRGC and PVAFRGC was found to be equal to $27 \mathrm{MPa}$ and $20 \mathrm{MPa}$. 


\subsection{Drying Shrinkage behaviour}

For repair and strengthening applications, the shrinkage of the new concrete is a crucial parameter for the response of the 'composite' elements [20]. In order to evaluate the shrinkage performance of SHGC, the drying shrinkage strain of SHGC, PVA-FRGC and OPC mortar was measured in accordance with ASTM C 490 [21]. A digital gauge was used and shrinkage measurements were taken at 1, 3, 5, 7, 14, 21, 28, 56, 90 and 120 days. Drying shrinkage measurements were started at $24 \mathrm{hrs}$ after casting. A series of prismatic specimens with cross-sectional dimensions of $75 \mathrm{~mm} \times 75 \mathrm{~mm}$ and length of $285 \mathrm{~mm}$ were used for the free shrinkage measurements The specimens were stored in a room with relative humidity $42 \%$ and temperature $20{ }^{\circ} \mathrm{C}$. The average drying shrinkage results of three replicate specimens for all the examined mixtures are presented in Figure 5.

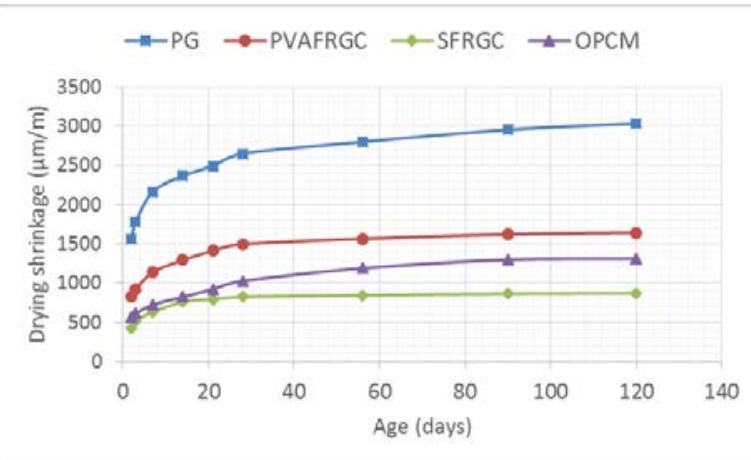

Figure 5. Dry shrinkage results up to 120 days

Based on the results of Figure 5 it is evident that the drying shrinkage strain of the plain geopolymer mortar (PG) is very high (around 3000 microstrains) at 120 days. This value is much higher than the respective strain value for plain OPC mortar (OPC) which was found to be around 1200 microstrains, a value which is in agreement with previous studies [22, 23]. The addition of fibres leads to significant reduction in shrinkage strain values in both cases (i.e. PVAFRGC and SFRGC), especially with the addition of steel fibres (SFRGC). In case of steel fibres (SFRGC) the shrinkage strain at 120 days was found equal to 850 microstrains, while in the case of PVA fibres (PVAFRGC) the respective value was found to be equal to 1600 microstrains. This reduction is attributed to the physical restraint provided by the presence of the fibres in the geopolymer matrix, which is in agreement with previous studies on conventional fibre reinforced concrete $[24,25]$. Li et al. [24] reported that the reduction of the drying shrinkage strain is considerably affected by the volume of the fraction of the fibres. Atis and Karahan [26] supported this finding and reported that the use of steel fibre restrained the movements at micro level in the case of fly ash and OPC based concrete by bridging and stitching the fine cracks.

\section{Strengthening of conventional concrete prisms with SHGC layers}

In all the examined specimens, concrete substrate was initially cast. One hour later, the surfaces of the initial prisms were roughened followed by the casting of $50 \mathrm{~mm}$ thick SHGC (SFRGC and PVAFRGC) layers. Normal strength concrete prisms with the same dimensions $(100 \mathrm{~mm} \times 100$ $\mathrm{mm} \times 500 \mathrm{~mm}$ ) were also cast and used as the control specimens. All the examined specimens were demoulded 48 hours after casting and wet cured (using water spraying) for the first two weeks to prevent shrinkage cracking and debonding at the SHGC-to-normal concrete interfaces. Flexural tests were conducted 6 months after casting (Figure 6). Standard fourpoint loading flexural tests were carried out according to the requirements of ASTM C1609 [19]. The testing setup is illustrated in Figure 6a and the failure modes of the strengthened samples with SFRGC layers are illustrated in Figures $6 \mathrm{~b}$ and $6 \mathrm{c}$. In the control concrete prisms, failure occurred with a single crack was developed and propagated under the loading point. Bending failure mode was also observed for SFRGC and PVAFRGC strengthened prisms, but in this case, multiple cracks were initially formed at the strengthening layer followed by propagation of one main crack to the initial conventional concrete prism. 'It should also be mentioned that even if quite high free shrinkage strain values have been measured for most of the examined specimens (Figure 5), shrinkage cracks were prevented in all the examined specimens by wet curing. 


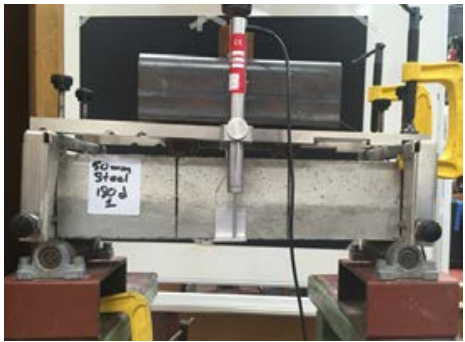

(a)

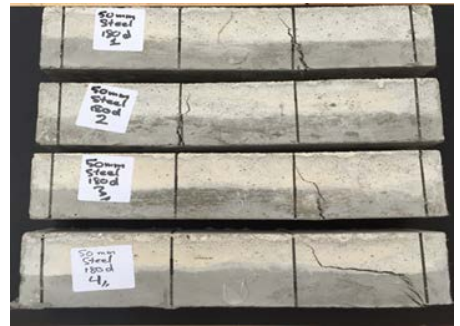

(b)

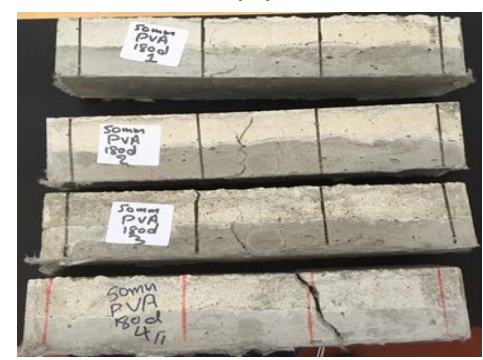

(c)

Figure 6. Concrete beam layered with $50 \mathrm{~mm}$ SFRGC: (a) flexural test configuration, (b) SFRGC composite beams after testing and (c) PVAFRGC composite beams after testing

The flexural load-deflection results for the normal strength prisms, which have been used as the control specimens for comparison, and the strengthened prisms with PVAFRGC and SFRGC layers are presented in Figure $7 a, 7 b$ and $7 c$ respectively. All the individual results together with the average curves are presented in Figure 7.

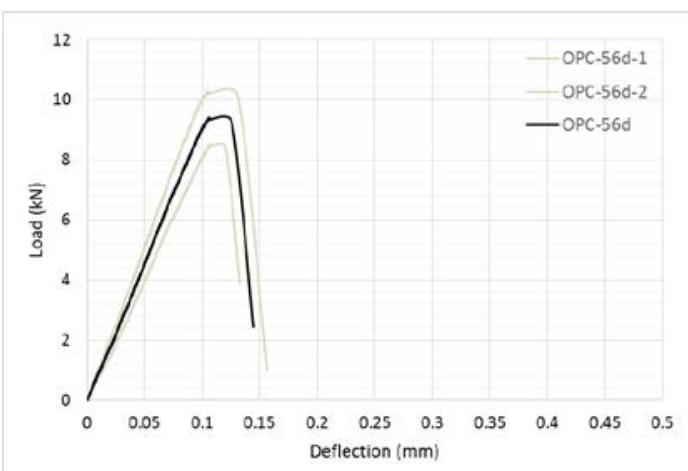

(a)

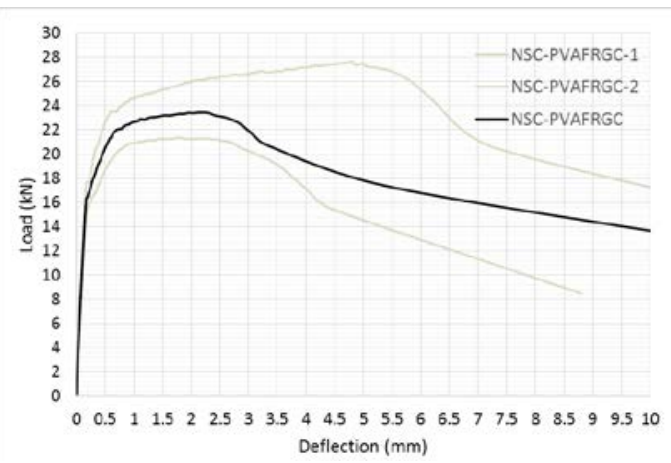

(b)

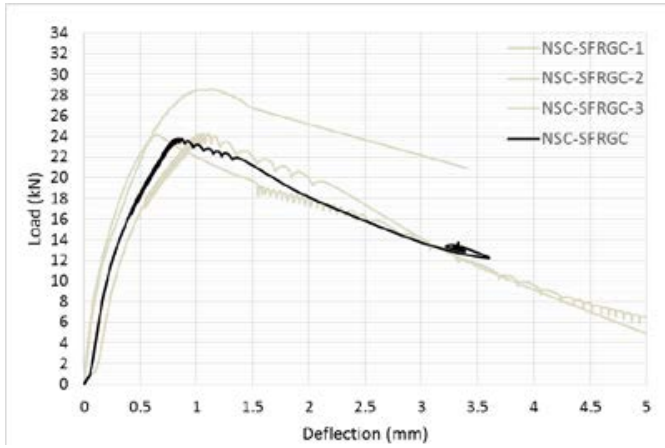

(c)

Figure 7. Flexural load versus deflection diagrams: (a) NSC prisms, (b) NSC prisms strengthened with PVAFRGC layers, and (c) NSC prisms strengthened with SFRGC

For plain normal strength concrete (NSC) beams, the average deflection at the peak load was found equal to $0.12 \mathrm{~mm}$ (Figure 7a). In the case of strengthened prisms with SFRGC layers (Figure 7c), the deflection at the peak load was increased to $0.87 \mathrm{~mm}$, which is 7 times higher compared to the control specimens. From the results of the strengthened prisms with PVAFRGC layers (Figure $7 b)$, it can be observed that the deflection at the peak load for these specimens was found to be equal to $2.3 \mathrm{~mm}$ which is almost 19 times higher compared to the control specimens' results. The considerably higher ductility of the composite/strengthened specimens was also evidenced by the failure mode of the examined specimens. In the case of the control specimens, cracks initiated at the mid span in the tensile side and propagated rapidly to the top of the compressive zone leading to fracture of the specimens into two pieces. The failure mode was completely different for the strengthened prisms with PVAFRGC/SFRGC layers, where crack-bridging by fibres gave high deflection values. Also, in the 
case of strengthened prisms, the maximum flexural load was considerably increased. The flexural load of the control concrete beam was found equal to $8 \mathrm{KN}$, while the respective values for prisms strengthened with SHGC and PVAFRGC layers were $24 \mathrm{kN}$ and $23.3 \mathrm{kN}$.

\section{Conclusions}

In this study the application of novel fibre reinforced geopolymer concretes for the strengthening of existing concrete beams was examined. The mechanical properties of SHGC materials were determined by compressive and flexural strength tests. The examined materials were found to have improved strain hardening performance under ambient temperature curing conditions. These materials were then applied for the strengthening of conventional concrete prisms and flexural tests were conducted in order to evaluate the efficiency of the proposed method.

Based on these experimental results of the current study, the following conclusions can be drawn:

- The compressive strength of the examined specimens was increased by $15 \mathrm{MPa}$ when steel fibres were added to the mix. The addition of PVA instead of steel fibres did not give the same pronounced improvement in compressive strength.

- The shrinkage strain of the plain geopolymer mix was reduced by $40 \%$ and $70 \%$ by the addition of PVA (PVAFRGC) and steel fibres (SFRGC) respectively.

- The strengthened prisms with SFRGC and/or PVAFRGC layers were found to have considerably improved ductility and maximum flexural strength capacity.

- The deflection at the peak load for the strengthened prisms, with SFRGC and PVAFRGC layers, was found to be almost 7 and 19 times higher than the respective value for the control specimens.

- The ultimate flexural strength of SFRGC strengthened specimens was similar to the ultimate strength of PVAFRGC strengthened elements. However, PVAFRGC strengthened elements exhibited significant deflection hardening behaviour and the ductility of these specimens was significantly improved.

\section{Acknowledgements}

The Iraqi Ministry of Higher Education and Scientific Research is gratefully acknowledged by the lead author for the financial support provided for this study, which is part of a PhD Scholarship.

\section{References}

1. Tokgoz, S., C. Dundar, and A.K. Tanrikulu, Experimental behaviour of steel fiber high strength reinforced concrete and composite columns. Journal of Constructional Steel Research, 2012. 74: p. 98-107.

2. Kim, D.J., et al., Comparative flexural behavior of Hybrid Ultra High Performance Fiber Reinforced Concrete with different macro fibers. Construction and Building Materials, 2011. 25(11): p. 4144-4155.

3. Olivito, R.S. and F.A. Zuccarello, An experimental study on the tensile strength of steel fiber reinforced concrete. Composites Part B: Engineering, 2010. 41(3): p. 246-255.

4. Li, V.C. and M. Li, Durability performance of ductile concrete structures. 2008.

5. Sahmaran, M., M. Li, and V.C. Li, Transport properties of engineered cementitious composites under chloride exposure. $\mathrm{ACl}$ Materials Journal, 2007. 104(6): p. 604-611.

6. Ahmed, S.F.U., M. Maalej, and P. Paramasivam, Flexural responses of hybrid steel-polyethylene fiber reinforced cement composites containing high volume fly ash. Construction and Building Materials, 2007. 21(5): p. 1088-1097.

7. Fischer, G. and V.C. Li, Effect of fiber reinforcement on the response of structural members. Engineering Fracture Mechanics, 2007. 74(1): p. 258-272.

8. Fischer, G. and V.C. Li, Deformation behavior of fiber-reinforced polymer reinforced engineered cementitious composite (ECC) flexural members under reversed cyclic loading conditions. $\mathrm{ACl}$ Structural Journal, 2003. 100(1): p. 25-35.

9. Yun, H.-D., Effect of accelerated freeze-thaw cycling on mechanical properties of hybrid PVA and $P E$ fiber-reinforced strain-hardening 
cement-based composites (SHCCS). Composites Part B: Engineering, 2013. 52: p. 11-20.

10.Spagnoli, A., A micromechanical lattice model to describe the fracture behaviour of engineered cementitious composites. Computational Materials Science, 2009. 46(1): p. 7-14.

11.Choi, W.-C., et al., Development of recycled strain-hardening cement-based composite (SHCC) for sustainable infrastructures. Composites Part B: Engineering, 2012. 43(2): p. 627-635.

12.Yun, H.-D., Flexural behavior and crack-damage mitigation of plain concrete beam with a strain-hardening cement composite (SHCC) layer at tensile region. Composites Part B: Engineering, 2013. 45(1): p. 377-387.

13.Al-Majidi, M.H., et al., Development of geopolymer mortar under ambient temperature for in situ applications. Construction and Building Materials, 2016. 120: p. 198-211.

14.Mohammed Al-Majidi, A.L., Andrew Cundy, Effect of Alkaline Activator, Water, Superplasticiser and Slag Contents on the Compressive Strength and Workability of SlagFly Ash Based Geopolymer Mortar Cured under Ambient Temperature. World Academy of Science, Engineering and Technology International Journal of Civil, Environmental, Structural, Construction and Architectural Engineering, 2016. 10(3).

15.Lee, N.K. and H.K. Lee, Setting and mechanical properties of alkali-activated fly ash/slag concrete manufactured at room temperature. Construction and Building Materials, 2013. 47(0): p. 1201-1209.

16.Al-Majidi, M.H., A. Lampropoulos, and A. Cundy, Strength and porosity of fly ash and slag based geopolymer mortar cured under ambient temperature with variant Silica Fume forms. Young Researchers' Forum III 2016, Innovation in Construction Materials, 2016.
17.Al-Majidi, M.H., A. Lampropoulos, and A.B. Cundy, Tensile properties of a novel fibre reinforced geopolymer composite with enhanced strain hardening characteristics. Composite Structures, 2017. 168: p. 402-427.

18.ASTM C109/C109M. Standard test method for compressive strength of hydraulic cement mortars (using $50 \mathrm{~mm}$ [2 in.] cube specimens). United States: ASTM Standards; 2007.

19.ASTM C1609 / C1609M-12, Standard Test Method for Flexural Performance of FiberReinforced Concrete (Using Beam With ThirdPoint Loading), ASTM International, West Conshohocken, PA, 2012,.

20.Lampropoulos, A.P., et al., Strengthening of reinforced concrete beams using ultra high performance fibre reinforced concrete (UHPFRC). Engineering Structures, 2016. 106: p. 370-384.

21.Sathia R, G.B., Manu Santhanam, Durability study of low calcium fly ash geopolymer concrete, in The 3rd ACF international conference. 2008. p. 1153-1159.

22.Lee, S.-J. and J.-P. Won, Shrinkage characteristics of structural nano-synthetic fibre-reinforced cementitious composites. Composite Structures, 2016. 157: p. 236-243.

23.Collins, F.G. and J.G. Sanjayan, Workability and mechanical properties of alkali activated slag concrete. Cement and Concrete Research, 1999. 29(3): p. 455-458.

24.Li, Z., M.A. Perez Lara, and J.E. Bolander, Restraining effects of fibers during non-uniform drying of cement composites. Cement and Concrete Research, 2006. 36(9): p. 1643-1652.

25.Zhang J., L.V.C., influence of Fibres on Drying Shrinkage of Fibre-Reinforced Cementitious Composite. Journal of Engineering Mechanics, ASCE, 2001. 127(1): p. 37-44.

26.Duran Atiş, C., et al., Influence of activator on the strength and drying shrinkage of alkaliactivated slag mortar. Construction and Building Materials, 2009. 23(1): p. 548-555. 